\title{
Integration of epidemiology into the genetic analysis of mastitis in Swedish Holstein
}

\author{
Jack J. Windig, ${ }^{* 1}$ Jorge I. Urioste, $† \ddagger$ and Erling Strandberg† \\ *Animal Breeding and Genomics Centre, Wageningen UR Livestock Research, 8200 AB Lelystad, the Netherlands \\ †Department of Animal Breeding and Genetics, Swedish University of Agricultural Sciences, PO Box 7023, S-75007 Uppsala, Sweden \\ łDepto. Prod. Animal y Pasturas, Fac. de Agronomía, UDELAR, Garzón 780, 12900 Montevideo, Uruguay
}

\section{ABSTRACT}

Heritability of mastitis (and diseases in general) tends to be low. One possible cause is that no clear distinction can be made between resistant and nonresistant animals, because healthy animals include animals that have not been exposed to pathogens and resistant animals. To account for this, we quantified the prevalence of clinical mastitis (CM) and subclinical mastitis (SCM) in 2,069 Swedish Holstein herds as a measure of exposure. Herd prevalence averaged 26.5\% for SCM and $6.4 \%$ for CM; $61 \%$ of the first lactations of 177,309 cows were classified as having at least one case of SCM and $10 \%$ as having CM. In a reaction norm approach, heritability of (S)CM was quantified as a function of herd prevalence of (S)CM. The best-fitting model was a second-order polynomial of first-lactation cow SCM as a function of herd prevalence SCM, and a first-order (linear) polynomial of first-lactation cow $\mathrm{CM}$ as a function of $\mathrm{CM}$ herd prevalence. Heritability for SCM ranged from 0.069 to 0.105 and for CM from 0.016 to 0.032 . For both, we found no clear effect of herd prevalence on their heritability. Genetic correlations within traits across herd prevalences were all greater than 0.92 . Whether relationships among prevalence, exposure, disease, and genetics were as expected is a matter of discussion, but reaction norm analyses may be a valuable tool for epidemiological genetics.

Key words: dairy cattle, disease prevalence, reaction norm, somatic cell count

\section{INTRODUCTION}

Mastitis is one of the most frequent and costly diseases in the dairy industry (Halasa et al., 2007; Huijps et al., 2008). Besides management, breeding is an important tool to reduce mastitis incidence. The advantage of reducing mastitis by breeding is that it results in a

Received August 23, 2012.

Accepted December 7, 2012.

${ }^{1}$ Corresponding author: jack.windig@wur.nl permanent change in the genetic composition of the dairy herd (Shook, 1989). The heritability of clinical mastitis (CM) is low, however, varying from 0.03 to 0.06 (Carlen et al., 2004; de Haas et al., 2008; Koeck et al., 2010). Frequently, SCC or SCC-derived traits, such as subclinical mastitis (SCM), are analyzed to facilitate genetic selection for mastitis resistance. Heritabilities of these traits are generally slightly higher than those for $\mathrm{CM}$ and vary from 0.05 to 0.16 in different studies (Windig et al., 2010; Martins et al., 2011; Zavadilova et al., 2011; Urioste et al., 2012). Because of these low heritabilities, it is difficult to estimate reliable breeding values and genetic progress can be slow.

Apart from low amounts of genetic diversity in resistance, other factors may cause low heritabilities. Failures in the registration of the disease (e.g., a low specificity or sensitivity of the test used to detect the disease) will lower the heritability. However, even if the registration of the disease is adequate, it can be difficult to distinguish between resistant and nonresistant animals if not all animals have been exposed to the pathogens causing the disease. For example, in a typical study analyzing the genetics of (sub)clinical mastitis $[(\mathbf{S}) \mathbf{C M}]$ using national recording schemes, healthy animals are a mixture of nonresistant animals that have not been exposed and resistant animals that may or may not have been in contact with pathogens. Bishop and Woolliams (2010a) derived formulas showing that incomplete exposure of animals to pathogens can reduce estimated heritabilities considerably, depending on the prevalence of the disease and the exposure probability. One way to account for this is to quantify the exposure probability and estimate heritabilities in environments differing in exposure probability.

Reaction norms are used to describe heritability and other genetic parameters over continuously varying environments. In such an approach, the phenotype is treated as a function of an environmental variable, and genetic variance components are estimated for the parameters describing the function. This enables the estimation of genetic parameters for each value that the environmental variable can take. In dairy cattle 
breeding, reaction norms have been used to analyze, for example, the genetics of production, fertility, and udder health (Calus and Veerkamp, 2003; Carlén et al., 2009; Windig et al., 2011).

In national milk recording schemes, SCC is generally recorded next to production traits across a large number of herds. In some Scandinavian countries, data on treatments for mastitis are recorded as well. Both SCC data and treatment data provide an opportunity to develop an indicator for exposure to mastitis pathogens. The idea is that when all animals in a herd are recorded, the fraction of animals with elevated SCC or animals treated at a given time (i.e., prevalence) will be closely related to the exposure probability of animals in the herd. Next, genetic parameters can be estimated as a function of the prevalence, using a reaction norm approach. By using polynomials for the functions describing the relationship between the genetic parameters and the herd prevalence, nonlinear relationships may be accounted for. The hypothesis is that, following Bishop and Woolliams (2010a), the heritability of mastitis increases with increasing prevalence.

In this study, mastitis in Swedish dairy herds was studied to determine whether the genetics of mastitis resistance is influenced by its prevalence. Data on mastitis treatments and SCC were available, so that both $\mathrm{CM}$ and SCM could be analyzed, either as a trait or as an environmental variable in the form of prevalence. In particular, the following questions were addressed: (1) Does the heritability of (S)CM increase with increasing prevalence? (2) Is the response different for prevalence of clinical mastitis compared with subclinical mastitis?

(3) What is the genetic correlation between (S)CM at different prevalences?

\section{MATERIALS AND METHODS}

\section{Data Set}

The data set was extracted from the Swedish milk recording scheme and included data on mastitis treatments and SCC. First lactations of all cows belonging to the Holstein breed that entered milk recording between 2002 and 2010 were included. Before edits, the number of animals was 178,613 . Test-days outside 5 to 366 DIM were excluded as well as test-days without recorded SCC. Only animals with age at calving between 19 and 38 mo were included. Offspring of bulls with fewer than 40 daughters or with offspring in fewer than 20 different herds were excluded. Finally, animals in herds with fewer than 10 animals after the edits were removed. The final data set included 2,069 herds with 177,309 first-lactation cows. These cows were sired by
762 sires and 5,581 maternal grandsires. The pedigree contained a total of 466,720 individuals.

\section{Definition of SCM and CM}

Recorded veterinary treatments for mastitis were used to analyze clinical mastitis per first-lactation cow. The trait CM was scored as a $0 / 1$ trait, with 1 indicating at least one case of treatment of clinical mastitis between $15 \mathrm{~d}$ before calving to $366 \mathrm{~d}$ after calving, and 0 indicating no treatment. The trait SCM was defined as 1 if the cow had at least one test-day during the lactation with a SCC $>150,000$ cells $/ \mathrm{mL}$, and otherwise as 0 . Although CM and SCM were recorded as $0 / 1$ traits, they were treated as continuous traits in subsequent analyses.

\section{Prevalence}

To quantify the prevalence of either CM or SCM, data of all animals present in the herds were used. These included not only the Holstein first-lactation cows for which the genetics were studied, but also animals in later lactations and animals of other breeds (mainly Swedish Red). The prevalence of SCM on a single test-day was defined as the fraction of all animals in the herd > 15 DIM that had an SCC >150,000 cells/ $\mathrm{mL}$ (following de Haas et al., 2008). Animals before 15 DIM were excluded because healthy cows may have SCC levels >150,000 cells/mL just after calving (de Haas et al., 2008).

Prevalence was used as the environmental variable in the reaction norm analysis as a proxy for exposure probability. Ideally, the prevalence should be measured over the period in which infection takes place. Because the traits (S)CM were defined on a whole-lactation basis, it was not clear over which period the prevalence should be defined. For SCM, 2 periods were used. First, the prevalence at the test-day at calving or at the first test-day before calving was used as the environmental value in the reaction norm analysis (SCMPREVday0). This may be the best period if we assume that most infections take place at the start or just before the start of the lactation. Second, the prevalence was averaged over all test-days that fell within the lactation period (SCMPREVday1-305). This may be the best period if infections are equally likely to occur over the whole lactation.

Similar to SCM, prevalence for CM was defined over 2 periods, 1 around the start of the lactation and 1 over the whole lactation. Prevalence of $\mathrm{CM}$ at the start of the lactation was defined as the fraction of animals in the herd that were treated for mastitis between $15 \mathrm{~d}$ be- 
fore calving $(\mathrm{d}-15)$ and $85 \mathrm{~d}$ after calving (CMPREVday-15-85). A 3-mo period was used because, for shorter periods, more than $50 \%$ of the herds were in the category of $0 \%$ prevalence. Because of the low prevalence of $\mathrm{CM}$, a 4 -wk period would have meant that more than $90 \%$ of the herds would have been scored as zero. The average of the 3 -mo periods occurring within the lactation was used as the herd prevalence over the whole lactation. However, this meant that for the largest category of $0 \%$ prevalence no cases of CM occurred, and variance in $\mathrm{CM}$ was equal to zero. Analysis with whole-lactation average for CM herd prevalence did not converge, probably for this reason, and only CMPREVday $-15-85$ will be reported hereafter.

\section{Genetic Analysis}

The 2 traits (CM and SCM) were analyzed using the following sire/maternal grandsire (MGS) model:

$$
\begin{aligned}
Y_{i j k l m} & =\mu+F I X E D+\sum \beta_{n, i} \Phi_{n}\left(\text { prev }_{k}\right) \\
& +0.5 \sum \beta_{n, j} \Phi_{n}\left(\text { prev }_{k}\right)+\varepsilon_{i j k l m},
\end{aligned}
$$

where $Y_{i j k l m}$ is $\mathrm{CM}$ or SCM of animal $m$, with sire $i$, grandsire $j$, and herd prevalence $k ; \mu$ is the average performance over all animals; FIXED includes herdyear-season subclasses $(\mathrm{n}=36,284)$, and second-order polynomial regressions on age at calving (in months) and prevalence of $(\mathrm{S}) \mathrm{CM}$ in the herd, herd-year-season subclasses were defined based on 3-mo periods covering winter (December to February), spring (March to May), summer (June to August), and fall (September to November); $\beta_{n, i}$ is the coefficient $n$ of the random regression on the orthogonal polynomials of $(\mathrm{S}) \mathrm{CM}$ of the daughters of sire $i ; \Phi_{n}\left(\right.$ prev $\left._{k}\right)$ ( $\mathrm{n}=0$ to $p$ ) are the design values of the orthogonal Legendre polynomials of order $p$ for the herd prevalence $k ; \beta_{n, j}$ is coefficient $\mathrm{n}$ of the random regression on the orthogonal polynomial of (S)CM of the maternal granddaughters of sire $j$; and $\varepsilon_{i j k l m}$ is the residual effect of cow $m$ in environment $k$ within group of environments $l$. The factor 0.5 was included because the incidence matrix of MGS effects was laid over the matrix of sire; that is, if a bull had entries in the data both as sire and MGS, his breeding value as MGS was equal to half the breeding value as a sire. Sire effects were linked using the relationship matrix of the sires and were assumed to be normally distributed, with $\operatorname{Var}\left(s_{\text {sire }}\right)=\operatorname{Var}\left(s_{\text {mgs }}\right)=\sigma_{s}^{2}$.

Because cows had a single observation in only one environment, residual effects could not be modeled as reaction norms. Therefore, residual variances were es- timated separately for groups of approximately 10,000 animals to account for heterogeneous residual variances. These groups were formed by ranking all animals based on herd prevalences. The first group was formed from all animals with a herd prevalence equal to or less than that of the 10,000th animal. This meant that for SCM at calving, the first group contained 11,371 animals, because animals ranked 9,016 to 11,371 shared their herd prevalence. For CM, this meant that the first group contained just over 39,877 animals, all of which had a herd prevalence of $0 \%$. Subsequent groups were formed by taking the herd prevalence of the next 10,000th animal. For SCM, 17 groups were formed, and for CM, 14 groups were formed.

The (co)variance matrix of the coefficients of the random regression were converted to a (co)variance matrix of (S)CM at herd prevalences. For a secondorder polynomial (i.e., with slopes and intercepts), the following equation was used:

$$
\mathbf{V}_{\text {herdprev }}=\mathbf{M}_{\Phi} \mathbf{V}_{R N} \mathbf{M}_{\Phi}^{\prime} \text { with } \mathbf{M}_{\Phi}=\left[\begin{array}{cc}
\Phi_{i n t, x 1} & \Phi_{s l, x 1} \\
\Phi_{i n t, x 2} & \Phi_{s l, x 2} \\
\vdots & \vdots \\
\Phi_{i n t, x n} & \Phi_{s l, x n}
\end{array}\right]
$$

where $\mathbf{V}_{\text {herdprev }}$ is the (co)variance matrix at a specific herd prevalence; $\mathbf{V}_{R N}$ the (co)variance matrix of the reaction norm with slopes $(s l)$ and intercepts (int); $x 1$, $x 2 \ldots x n$ are $n$ points along the environmental gradient of herd prevalences; and $\Phi_{\text {int }, x \#}$ and $\Phi_{s l, x \#}$ are the design values for the linear function used in the reaction norm model. The points along the environmental gradient were the average herd prevalences of the groups described in the previous paragraph. Heritabilities were calculated as $h^{2}=4 \sigma_{s}^{2} /\left(\sigma_{R}^{2}+1.25 \sigma_{s}^{2}\right)$, with $\sigma_{R}^{2}$ being the residual variance. The last term $\left(1.25 \sigma_{s}^{2}\right)$ was included because both sire effects $\left(1 \times \sigma_{s}^{2}\right)$ and MGS effects $\left(0.25 \times \sigma_{s}^{2}\right)$ were included in the model.

All analyses were done with REML using the software package ASReml (Gilmour et al., 2006). Both $\mathrm{CM}$ and SCM were analyzed with herd prevalence of subclinical mastitis (SCMPREVday0 and SCMPREVday1-305) and herd prevalence of clinical mastitis (CMPREVday-15-85). Analyses started with a zeroorder polynomial (i.e., constant sire variance over all herd prevalences, differences in heritabilities only due to differences in residual). In subsequent analyses, the order was increased, until the maximum likelihood at which the model converged decreased. 


\section{RESULTS}

\section{Prevalence}

On a single test-day, on average, $26.5 \%$ of the cows in a herd had an SCC $>150,000$ cells $/ \mathrm{mL}$, indicating $\mathrm{SCM}$, and in $61 \%$ of the cow lactations at least one test-day with SCC >150,000 cells/mL occurred. Herd prevalences on single test-days ranged from 0 to $100 \%$, with $98 \%$ of the prevalences in the range of 9 to $50 \%$
(Figure 1). Prevalence was lower in 2002 and 2003 (average $21.6 \%$ ) than in later years (2004 to 2010), when it remained constant at $28.0 \%$, on average. In these later years, winter and spring prevalence was lower (26.4\%) than summer and autumn prevalence (29.3\%).

The herd prevalence of CM in 3-mo periods averaged $6.4 \%$, and at least one treatment of mastitis occurred in $10 \%$ of the lactations of the Holstein first-lactation cows. In $25.1 \%$ of the 3 -mo periods, herd prevalence was $0 \%$, whereas $97.5 \%$ of the periods had a preva-
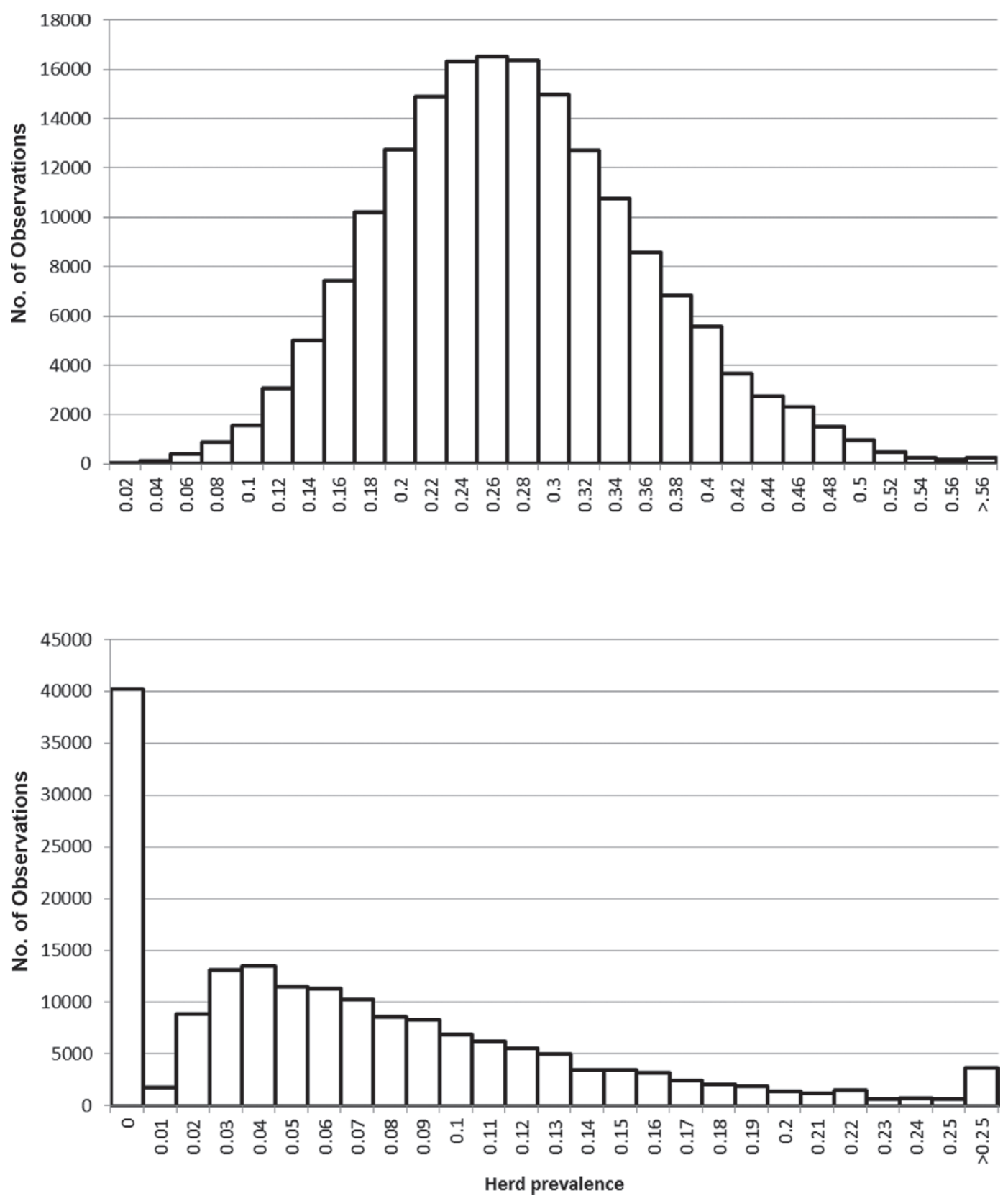

Figure 1. Distribution of first-lactation cows according to prevalence of subclinical mastitis (top) and clinical mastitis (bottom) in their herds. 
lence of $25 \%$ or less (Figure 1). Herd prevalence of CM increased from $3.8 \%$ in 2002 to $7.2 \%$ in 2010 . Herd prevalence was lower in summer $(6.0 \%)$ than during the rest of the year (average $7.0 \%$ ).

Ten percent of the first-lactation cows had at least one case of SCM during their lactation when no cases of SCM occurred in their herd at the start of their lactation (Figure 2). This percentage increased to $50 \%$ at a herd prevalence of $20 \%$ and to $95 \%$ at a herd prevalence of $65 \%$. The percentage of first-lactation cows with $\mathrm{CM}$ did not increase with increasing herd prevalence of SCM, except above a herd prevalence of SCM above $50 \%$ (Figure 2). About $10 \%$ of the first-lactation cows had at least one case of $\mathrm{CM}$ in their lactation below a herd prevalence of $50 \%$ SCM. This number increased to $18 \%$ at a herd prevalence of SCM of $70 \%$. The percentage of first-lactation cows with SCM did increase somewhat with increasing herd prevalence of CM (Figure 3): from $58 \%$ at a prevalence of $7.5 \%$ to $70 \%$ at a prevalence of $50 \%$. In other words, a higher prevalence of CM does not lead directly to more SCM, nor does a higher prevalence of SCM lead to more CM. Only at the highest prevalences did there seem to be a weak relationship.

\section{Reaction Norms}

The best fitting model for SCM was a second-order polynomial reaction norm with SCMPREVday1-305 as the environmental variable (Table 1). The maximum likelihood (ML) for such a model was considerably higher $(2,772)$ than for a model with SCMPREVday0 $(1,820)$, or CMPREVday-15-85 (1,512). A constant or linear reaction norm fitted somewhat less well (ML of 2,530 and 2,755, respectively). A third-order polynomial had only a slightly lower ML $(2,768)$.

The best-fitting model for $\mathrm{CM}$ was a linear reaction norm with CMPREVday-15-85 as the environmental variable (Table 1 ). The ML for such a model was substantially larger $(17,250)$ than that for a model with SCMPREVday1-305 (3,271). Constant and secondorder polynomial reaction norms also clearly fitted less well (ML of 17,100 and 17,166, respectively). Hereafter, results will only be presented for the best-fitting models (i.e., second-order polynomial of SCM and a linear reaction norm for CM, both with their own herd prevalence as the environmental factor).

\section{Variance Components and Heritabilities}

The total variance in a binary trait (0 or 1$)$ such as SCM depends on the frequency of positive cases $(p)$, and follows $p(1-p)$, so that its maximum is reached at a frequency of $50 \%$. Trait SCM reached a frequency of $50 \%$ when SCMPREVday1-305 was around 20\% (Figure 2). Maximal values for the residual variance component, which makes up the largest part of the total variance, were indeed observed around 20\% SCMPREVday1-305 (Figure 4). The additive variance component and heritability for SCM followed a different pattern. The additive variance component decreased over the whole range of SCMPREVday1-305. This decrease was

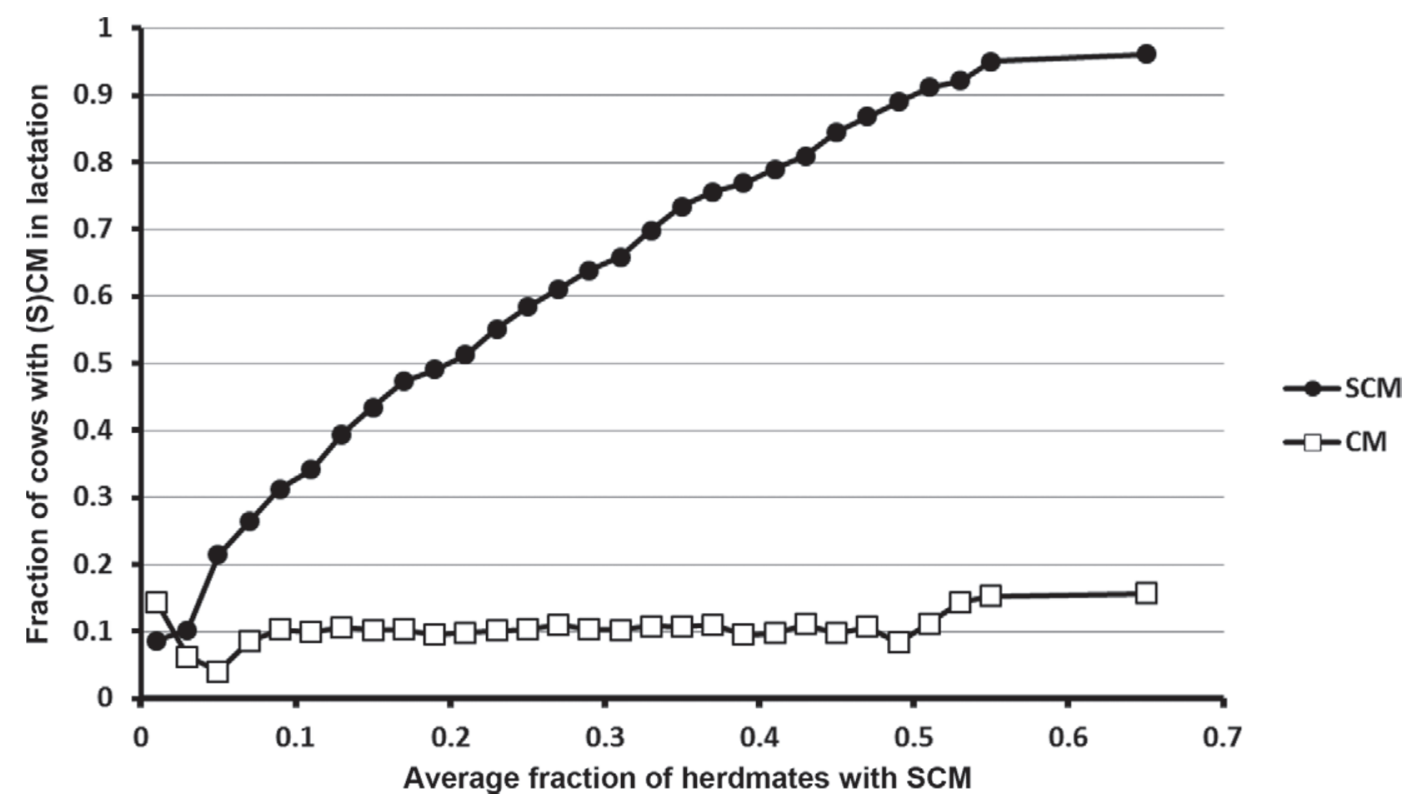

Figure 2. Fraction of first-lactation cows with at least one case of subclinical mastitis (SCM) or clinical mastitis (CM) in their lactation versus mean herd prevalence of subclinical mastitis on a test-day basis at the start of the lactation. 
Table 1. Maximum log-likelihood values of random regression REML analyses of subclinical mastitis (SCM) and clinical mastitis (CM) versus prevalence of SCM or CM and different order polynomials

\begin{tabular}{|c|c|c|c|c|c|}
\hline \multirow[b]{2}{*}{$\begin{array}{l}\text { Order of } \\
\text { polynomial }\end{array}$} & \multicolumn{3}{|c|}{ SCM versus: } & \multicolumn{2}{|c|}{$\mathrm{CM}$ versus: } \\
\hline & $\begin{array}{l}\text { Prevalence of } \\
\text { SCM at calving }\end{array}$ & $\begin{array}{l}\text { Lactation-average } \\
\text { prevalence of SCM }\end{array}$ & $\begin{array}{l}\text { Prevalence } \\
\text { of CM }\end{array}$ & $\begin{array}{l}\text { Lactation-average } \\
\text { prevalence of SCM }\end{array}$ & $\begin{array}{l}\text { Prevalence } \\
\text { of CM }\end{array}$ \\
\hline 0 & 1,785 & 2,530 & 1,019 & 3,271 & 17,100 \\
\hline 1 & 1,818 & 2,755 & 1,512 & 3,270 & 17,250 \\
\hline 2 & 1,820 & 2,772 & 1,498 & 3,267 & 17,166 \\
\hline 3 & 1,818 & 2,768 & & & $\mathrm{NC}^{1}$ \\
\hline
\end{tabular}

${ }^{1}$ Not converged.

relatively less than the decrease of the residual variance component, causing a slight increase in heritability at SCMPREVday1-305 above 25\%. We observed a slight decrease in heritability of SCM between 11 and $25 \%$ SCMPREVday1-305. The heritability for SCM varied between 0.069 and 0.105 (Table 2). Standard errors indicated no significant differences between heritabilities at different herd prevalences.

Heritability for CM was clearly lower than that for SCM. The maximum heritability was 0.03 observed at 0\% CMPREVday-15-85 (Figure 5). Heritability decreased to a minimum of 0.02 at a prevalence of $7.5 \%$, after which it increased slightly. Standard errors indicated no differences between heritabilities at different herd prevalences. Both the additive and residual variance components increased with increasing herd prevalences, as expected for a binary trait for which the total variance increases up to a frequency of $50 \%$ cases.
Genetic correlations within traits between environments were strong both for SCM (Table 2) and CM (Table 3). The lowest genetic correlations were found between the most extreme environments. The genetic correlation for SCM between a herd prevalence of 11 and $47 \%$ was 0.91 (SE 0.082). The genetic correlation for CM between a herd prevalence of 0 and $25 \%$ was 0.95 (SE 0.0624).

\section{DISCUSSION}

Models in which the additive variance was allowed to change as a function of the prevalence of (S)CM had a better fit than models with a constant additive variance across prevalences of (S)CM. However, the heritability of (S)CM did not clearly increase with increasing prevalence, as was expected based on the Bishop and Woolliams (2010a) model. Estimates for heritability of



Figure 3. Percentage of first-lactation cows with at least one case of subclinical (SCM) or clinical mastitis (CM) in their lactation versus average herd prevalence of subclinical mastitis on a 3-mo basis around the start of the lactation. 
Table 2. Heritability (in bold on diagonal, with SE parentheses) and genetic correlations of subclinical mastitis at 4 prevalences

\begin{tabular}{|c|c|c|c|c|}
\hline \multirow[b]{2}{*}{ Prevalence } & \multicolumn{4}{|c|}{ Prevalence } \\
\hline & $11.3 \%$ & $23.7 \%$ & $34.5 \%$ & $46.7 \%$ \\
\hline $11.3 \%$ & $0.080(0.011)$ & & & \\
\hline $23.7 \%$ & 0.99 & $0.069(0.005)$ & & \\
\hline $34.5 \%$ & 0.96 & 0.99 & $0.077(0.006)$ & \\
\hline $46.7 \%$ & 0.92 & 0.95 & 0.98 & $0.105(0.014)$ \\
\hline
\end{tabular}

$\mathrm{CM}$ in our research ranged from 0.02 to 0.03 . Other studies reported values of 0.01 to 0.03 (Carlén et al., 2004), 0.01 to 0.02 (de Haas et al., 2008), and 0.02 to 0.06 (Koeck et al., 2010). Thus, values and ranges in those studies were similar to or larger than those in our study, whereas variation within those studies was between lactation stages or parities, rather than prevalences.

For SCM, we estimated heritability between 0.07 and 0.11 . Numerous studies have reported the heritability of SCS, which is related to our SCM trait. Recent studies report values for heritability of SCS between 0.05 and 0.07 (Windig et al., 2011), 0.05 and 0.09 (Martins et al., 2011), 0.08 and 0.14 (Zavadilova et al., 2011), 0.11 and 0.14 (Rzewuska et al., 2011), and 0.10 and 0.15 (Elsaid et al., 2011). Thus, as with CM, the range of values for heritability of SCS, without taking variation in prevalence into account, was similar to heritability of SCM in our study. Calus et al. (2006) reported heritability of SCS over lactation stage and bulk milk SCS. The latter might be seen as related to SCM prevalence. They reported an increase from 0.06 to 0.10 with increasing bulk milk SCS early in lactation, but a decrease from 0.16 to 0.11 late in lactation.

Results reported in our study are based on (S)CM as a categorical trait, as in Bishop and Woolliams (2010a). Heritabilities on an underlying continuous scale are generally higher, especially at low or high frequencies of affected animals (e.g., $<10 \%$ or $>90 \%$; Meijering and Gianola, 1985). A simple transformation using the Dempster and Lerner (1950) equations, combining the percentages of Figure 2 and heritabilities of Table 2, indicated that heritabilities for SCM at the underlying scale increased from about 13 to $18 \%$. Likewise, heritabilities for CM, using Figure 3 and Table 3, decreased at the underlying scale from 15 to $5 \%$. In conclusion, we found no clear evidence of increasing heritability with increasing prevalences for $\mathrm{CM}$ or SCM, whether on the $0 / 1$ scale or on the underlying continuous scale.

In the Bishop and Woolliams (2010a) model, the reason for the increase of heritability with increasing prevalences is that variation in exposure within a herd (e.g., some animals are exposed to pathogens and others not) is minimized or even eliminated at higher prevalences.



Figure 4. Variance components and heritability of subclinical mastitis (SCM) estimated for different prevalences of subclinical mastitis in the herd. 
Table 3. Heritability (SE) in bold on diagonal and genetic correlations of clinical mastitis at 4 different prevalences

\begin{tabular}{llllc}
\hline & \multicolumn{3}{c}{ Prevalence } \\
\cline { 2 - 4 } Prevalence & \multicolumn{1}{c}{$0.0 \%$} & \multicolumn{1}{c}{$8.0 \%$} & $12.8 \%$ & $24.5 \%$ \\
\hline $0.0 \%$ & $\mathbf{0 . 0 3 2 ( \mathbf { 0 . 0 0 7 } )}$ & $\mathbf{0 . 0 1 6 ( \mathbf { 0 . 0 0 2 } )}$ & & \\
$8.0 \%$ & 0.99 & 0.998 & $\mathbf{0 . 0 1 8}(\mathbf{0 . 0 0 3})$ & \\
$12.8 \%$ & 0.98 & 0.99 & 0.996 & $\mathbf{0 . 0 2 7}(\mathbf{0 . 0 0 5})$ \\
$24.5 \%$ & 0.95 & &
\end{tabular}

The use of herd level of (S)CM as a measure of prevalence in the current study might not be adequate. The relationship between prevalence of (S)CM and infection pressure is not known. The assumption is that exposure to pathogens increases with herd prevalence. One possibility is that exposure did not increase over the range of prevalences in our study. For example, animals might be exposed to sufficient pathogens to become infected only above $50 \%$ prevalence of SCM. Indeed, when we extended our estimates up to $75 \%$ prevalence, the heritability more than doubled, but we cannot rely on these values because of insufficient data in that range. The other extreme is that even at low levels of prevalence all animals might be exposed to sufficient pathogens to become infected, so that across the whole range of prevalences in our study all susceptible animals would become diseased.

Another reason for the lack of a clear increase in heritability with increasing prevalences might be that our measure of the disease was not adequate. In other words, the specificity or sensitivity of our measures of (S)CM might be low. We defined $\mathrm{CM}$ as requiring a veterinary treatment for mastitis. Mörk at al. (2009) showed that variation existed in treatment between Swedish herds (in part, using the same herds as in the current study) that was not caused by variation in mastitis. For example, mastitis early in lactation was more often treated, as was mastitis in herds of farmers with good recordkeeping. Bishop and Woolliams (2010b) give formulas to account for variation in specificity and sensitivity. The effect is similar to incomplete exposure: lower levels of specificity and sensitivity cause a decrease in heritability.

Exposure levels might also decrease with higher levels of herd prevalence of CM; again, CM was defined based on treatments. A treatment of mastitis would, if successful, result in fewer diseased animals and lower infection pressures, in contrast to the assumption here that a higher prevalence of CM would lead to higher exposure. This may also be the cause of the weak relationship between the prevalence of CM and SCM (Figures 2 and 3). We have attempted to estimate the genetic correlation between SCM and $\mathrm{CM}$ in a bivariate reaction norm analysis, with either SCM or CM prevalence

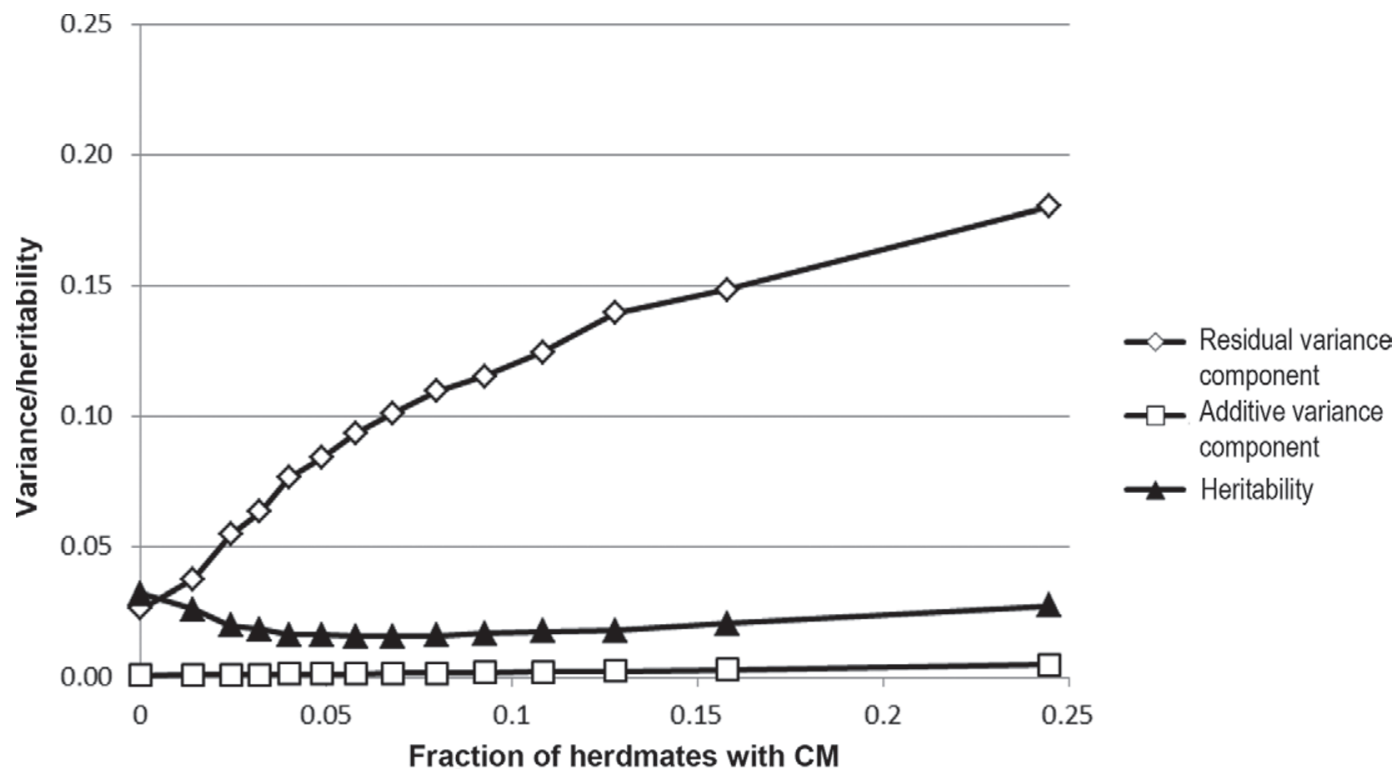

Figure 5. Variance components and heritability of clinical mastitis $(\mathrm{CM})$ estimated for different prevalences of clinical mastitis in the herd. 
as the environmental variable. However, these analyses did not converge, likely due to the low genetic variation in CM, which impedes estimation of covariances between the coefficients of polynomials.

Subclinical mastitis was defined as at least one testday in the lactation with a $\mathrm{SCC}>150,000$ cells $/ \mathrm{mL}$. This trait was chosen because a threshold trait, rather than the average SCS, better distinguishes milk quarters with and without pathogens (ten Napel et al., 2009). However, in practice, the distinction in SCS of diseased and healthy cows is not sharply defined and healthy cows can have higher SCS and diseased cows lower SCS than the threshold. Moreover, different threshold values are reported in the literature. One solution is to use information from other traits to distinguish healthy and diseased cows, such as milk yield, which decreases due to mastitis infections (Jamrozik and Schaeffer, 2010). Another alternative is to use sets of traits derived from SCC that describe different aspects of mastitis infections or may be related to different types of pathogens. These traits include traits such as average SCS in different stages of lactation, peak patterns of SCS, different thresholds of SCC, and standard deviation of SCS (de Haas et al., 2008; Windig et al., 2010; Koeck et al., 2012; Urioste et al., 2012).

The ideas behind the Bishop and Woolliams (2010a) model may not apply in all situations. One idea is that the distinction between resistant and susceptible animals becomes clear only if all animals are exposed. However, with high levels of pathogens, the infection pressure may become so high that even the most resistant animals will become diseased. In that case, higher heritabilities may be expected at low or intermediate prevalences. Bishop and Woolliams (2010b) give a model for 3 genotypes in which variation in resistance is dose dependent. In that model, variation between genotypes is largest at intermediate levels of exposure and absent at low and high levels. We did not find patterns with higher levels at intermediate exposure, but nevertheless more information on the dose dependence of (S)CM may improve reaction norm models as used in this study.

In this study, (S)CM was analyzed on a lactation basis. A logical next step would be to analyze results on a test-day basis, so that not only infection can be analyzed, but also recovery. This, however, requires more than an analysis of (S)CM as a 0/1 trait with repeated observations, because the order of affected test-days is important as well. For example, 2 consecutive test-days with a case of $(\mathrm{S}) \mathrm{CM}$ is different from 1 case at the start and 1 case at the end of the lactation. An approach whereby the probability of infection is estimated (e.g., Franzén et al., 2012) combined with a reaction norm analysis with prevalence as the environmental variable would capture this information.

\section{CONCLUSIONS}

The log-likelihood of the genetic models was largest when information on the herd prevalence of the trait itself was included in the model. When the additive variance was allowed to change as a function of herd prevalence, the log-likelihood increased further. Thus, more or better information on herd prevalence may increase the fit of reaction norm models. However, this did not result in a clear and statistically significant change of heritability over herd prevalences. Although results were not clear cut in this study, reaction norms can be a valuable tool for analysis of epidemiological genetics.

\section{ACKNOWLEDGMENTS}

We are grateful to the Swedish Dairy Association (Svensk Mjölk, Stockholm, Sweden) and farmers for providing the data set that was analyzed in this study. This work was carried out as part of the RobustMilk project that is financially supported by the European Commission under the Seventh Research Framework Programme (Grant Agreement KBBE-211708). The content of this paper is the sole responsibility of the authors, and it does not necessarily represent the views of the Commission or its services

\section{REFERENCES}

Bishop, S. C., and J. A. Woolliams. 2010a. On the genetic interpretation of disease data. PLoS ONE 5:e8940.

Bishop, S. C., and J. A. Woolliams. 2010b. Understanding field disease data. Contribution 0401 in Proc. 9th World Congr. Genet. Appl. Livest., Leipzig, Germany.

Calus, M. P. L., L. L. G. Janss, and R. F. Veerkamp. 2006. Genotype by environment interaction for somatic cell score across bulk milk somatic cell count and days in milk. J. Dairy Sci. 89:4846-4857.

Calus, M. P. L., and R. F. Veerkamp. 2003. Estimation of environmental sensitivity of genetic merit for milk production traits using a random regression model. J. Dairy Sci. 86:3756-3764.

Carlén, E., K. Grandinson, U. Emanuelson, and E. Strandberg. 2009. Random regression models for genetic evaluation of clinical mastitis in dairy cattle. Animal 3:1100-1108.

Carlén, E., E. Strandberg, and A. Roth. 2004. Genetic parameters for clinical mastitis, somatic cell score, and production in the first three lactations of Swedish Holstein cows. J. Dairy Sci. 87:30623070 .

de Haas, Y., W. Ouweltjes, J. ten Napel, J. J. Windig, and G. de Jong. 2008. Alternative somatic cell count traits as mastitis indicators for genetic selection. J. Dairy Sci. 91:2501-2511.

Dempster, E. R., and I. M. Lerner. 1950. Heritability of threshold characters. Genetics 35:212-236.

Elsaid, R., A. Sabry, M. S. Lund, and P. Madsen. 2011. Genetic analysis of somatic cell score in Danish dairy cattle using random regression test-day model. Livest. Sci. 140:95-102. 
Gilmour, A. R., B. J. Gogel, B. R. Cullis, and R. Thompson. 2006. ASReml User Guide. Release 2.0. VSN International Ltd., Hemel Hempstead, UK.

Franzén, J., D. Thorburn, J. I. Urioste, and E. Strandberg. 2012. Genetic evaluation of mastitis liability and recovery through longitudinal analysis of transition probabilities. Genet. Sel. Evol. 44:10.

Halasa, T., K. Huijps, O. Osteras, and H. Hogeveen. 2007. Economic effects of bovine mastitis and mastitis management: A review. Vet. Q. 29:18-31.

Huijps, K., T. Lam, and H. Hogeveen. 2008. Costs of mastitis: Facts and perception. J. Dairy Res. 75:113-120.

Jamrozik, J., and L. R. Schaeffer. 2010. Application of multiple-trait finite mixture model to test-day records of milk yield and somatic cell score of Canadian Holsteins. J. Anim. Breed. Genet. 127:361368.

Koeck, A., B. Heringstad, C. Egger-Danner, C. Fuerst, P. Winter, and B. Fuerst-Waltl. 2010. Genetic analysis of clinical mastitis and somatic cell count traits in Austrian Fleckvieh cows. J. Dairy Sci. 93:5987-5995.

Koeck, A., F. Miglior, D. F. Kelton, and F. S. Schenkel. 2012. Alternative somatic cell count traits to improve mastitis resistance in Canadian Holsteins. J. Dairy Sci. 95:432-439.

Martins, A. M., A. M. Silvestre, M. F. Petim-Batista, and J. A. Colaco. 2011. Somatic cell score genetic parameter estimates of dairy cattle in Portugal using fractional polynomials. J. Anim. Sci. $89: 1281-1285$.

Meijering, A., and D. Gianola. 1985. Linear versus nonlinear methods of sire evaluation for categorical traits: A simulation study. Genet. Sel. Evol. 17:115-132.
Mörk, M. J., U. Emanuelson, A. Lindberg, I. Vagsholm, and A. Egenvall. 2009. Herd and cow characteristics affecting the odds of veterinary treatment for disease $-\mathrm{A}$ multilevel analysis. Acta Vet. Scand. 51:34

Rzewuska, K., J. Jamrozik, A. Zarnecki, and T. Strabel. 2011. Genetic parameters of test-day somatic cell scores for the first three lactations of Polish Holstein-Friesian cattle. Czech J. Anim. Sci $56: 381-389$.

Shook, G. E. 1989. Selection for disease resistance. J. Dairy Sci 72:1349-1362.

ten Napel, J., Y. De Haas, G. De Jong, T. J. G. M. Lam, W. Ouweltjes, and J. J. Windig. 2009. Characterization of distributions of somatic cell counts. J. Dairy Sci. 92:1253-1264.

Urioste, J. I., J. Franzen, J. J. Windig, and E. Strandberg. 2012. Genetic relationships among mastitis and alternative somatic cell count traits in the first 3 lactations of Swedish Holsteins. J. Dairy Sci. 95:3428-3434.

Windig, J. J., H. A. Mulder, D. I. Bohthe-Wilhelmus, and R. F. Veerkamp. 2011. Simultaneous estimation of genotype by environment interaction accounting for discrete and continuous environmental descriptors in Irish dairy cattle. J. Dairy Sci. 94:31373147.

Windig, J. J., W. Ouweltjes, J. ten Napel, G. de Jong, R. F. Veerkamp, and Y. De Haas. 2010. Combining somatic cell count traits for optimal selection against mastitis. J. Dairy Sci. 93:1690-1701.

Zavadilova, L., J. Wolf, M. Stipkova, E. Nemcova, and J. Jamrozik. 2011. Genetic parameters for somatic cell score in the first three lactations of Czech Holstein and Fleckvieh breeds using a random regression model. Czech J. Anim. Sci. 56:251-260. 